\title{
Synthesis, characterisation and dissolution of simulant Chernobyl and Fukushima Fuel Debris
}

\author{
C. Gausse, M. Stennett, D. Bailey, S. BARlow,
} H. Ding, M. S. LAWSON, N. HYATT AND C. CORKHILL ${ }^{1}$

${ }^{1}$ NucleUS Immobilisation Science Laboratory, The

University of Sheffield, UK, c.corkhill@sheffield.ac.uk

Relatively few samples of fuel debris materials from nuclear accidents are available for study, and their analysis is made challenging due to the radiation hazard associated with their handling. Therefore, the synthesis of low-radioactivity (i.e. depleted uranium only) simulants has been performed to help to support ongoing decommissioning operations, for example at the Chernobyl Nuclear Power Plant (CNPP) and the Fukushima Daiichi Nuclear Power Plant (1F). In collaborative projects with Ukrainian and Japanese partners, we have developed a suite of simulant nuclear fuel debris to approximate materials formed by reaction of $\mathrm{UO}_{2}$ pellets with the steam-oxidised zircaloy fuel cladding, and also those formed by melting of this materials with other reactor components.

Compositions in the $\mathrm{U}_{1-\mathrm{x}} \mathrm{Zr}_{\mathrm{x}} \mathrm{O}_{2}, \mathrm{U}_{1-\mathrm{x}} \mathrm{Ln}_{\mathrm{x}} \mathrm{O}_{2}$ and $\mathrm{U}_{1-}$ $(\mathrm{x}+\mathrm{y}) \mathrm{Ln}_{\mathrm{x}} \mathrm{Zr}_{\mathrm{y}} \mathrm{O}_{2 \pm \mathrm{z}}$ solid solutions $(\mathrm{Ln}=\mathrm{Ce}, \mathrm{Nd})$ were prepared with $4 \mathrm{wt} \% \mathrm{Ce}$ or $\mathrm{Nd}$ as surrogates for $\mathrm{Pu}$ and lanthanide fission products, respectively. These compositions were mixed, at appropriate concentrations, with oxides representative of the reactor building components, for example, relevant concrete compositions, serpentinite (at CNPP) and stainless steel. The resulting materials (known as Lava-like Fuel Containing Materials (LFCM) at CNPP and Molten Core-Concrete Interaction products (MCCIs) at 1F) were characterized by laboratory (SEM/EDS, XRD, TGA) and micro-focus synchrotron techniques ( $\mu$-XRD, $\mu$-XRF, $\mu$ XANES) and were found to contain all of the expected $\mathrm{U}-\mathrm{Zr}$ $\mathrm{O}$ phases, in addition to U-rich zircon, referred to as "chernobylite" $\left[\left(\mathrm{Zr}_{1-\mathrm{x}} \mathrm{U}_{\mathrm{x}}\right) \mathrm{SiO}_{4}\right]$, which was present as inclusions in a calcium aluminosiliciate glass matrix.

Utilisation of micro-focus XAS and XRD techniques allowed identification of the distribution of the Pu surrogate, $\mathrm{Ce}$, in an effort to support fissile material accountancy when fuel debris is removed from the reactor buildings. We also present preliminary data of the long-term corrosion of these materials acquired during a long-term in-situ synchrotron radiation XRD experiment performed at Diamond Light Source. 